\title{
Synthesis of four diastereomers and structural revision of tetradenolide
}

Maki Tokuda, ${ }^{\mathrm{b}}$ Yuji Kurogome, ${ }^{\mathrm{a}}$ Rieko Katoh, ${ }^{\mathrm{a}}$ Yukie Nohara, ${ }^{\mathrm{b}}$ Yasunao Hattori, ${ }^{\mathrm{c}}$ and Hidefumi Makabe*a

${ }^{\mathrm{a}}$ Graduate School of Agriculture, Sciences of Functional Foods, Shinshu University,

8304 Minami-minowa Kami-ina, Nagano, 399-4598, Japan

${ }^{\mathrm{b}}$ Department of Bioscience and Biotechnology, Faculty of Agriculture, Shinshu University, 8304 Minami-minowa Kami-ina, Nagano, 399-4598, Japan

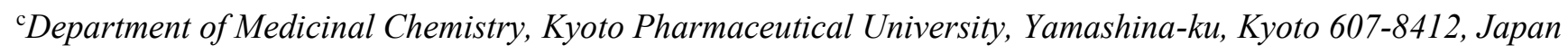

*Corresponding author. Tel. +81 26577 1630; fax +81 26577 1700; e-mail: makabeh@ shinshu-u.ac.jp

\begin{abstract}
Four diastereomers of tetradenolide, a cytotoxic $\alpha$-pyrone isolated from Tetradenia riparia, were synthesized stereoselectively using Z-selective Horner-Emmons reaction followed by acid catalyzed lactonization. Making comparison of the ${ }^{1} \mathrm{H}$ and ${ }^{13} \mathrm{C}$ NMR spectral data of the four diastereomers with those of the reported value of natural product did not lead to determine the relative stereochemistry of the natural tetradenolide. Thus detailed investigation of the spectral data of the related compounds led us to revise the structure of tetradenolide as deacetylboronolide.
\end{abstract}

Key words: tetradenolide, $\alpha$-pyrone, structural revision, total synthesis

Tetradenolide is an antimicrobial, phytotoxic and cytotoxic $\alpha$-pyrone isolated by Luc Van Puyvelde and De Kimpe from Tetradenia riparia. ${ }^{1}$ The related compound (+)-deacetylboronolide was isolated Luc Van Puyvelde and co-workers from the same plant, Tetradenia riparia (Hochst) N. E. Br. (Labiatae) ${ }^{2}$ and (+)-boronolide was isolated from Tetradenia fruticosa Benth and Tetradenia barbera (N. E. Br.) Codd, respectively. ${ }^{3,4}$ As to the biological activity of boronolides, anti-malarial activity was reported (Figure 1). ${ }^{2,5}$ Many reports of the syntheses of (+)-boronolide and (+)-deacetylboronolide have been published so far. ${ }^{6}$ However, synthetic study of teradenolide has not been reported yet. The reported structure of tetradenolide was shown in Figure 1 and the relative stereochemistry and optical rotation value of this compound were not reported. ${ }^{1}$

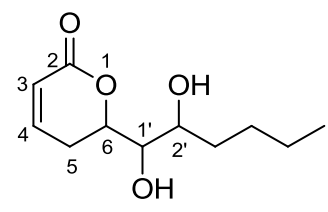

tetradenolide

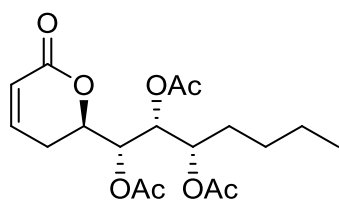

boronolide

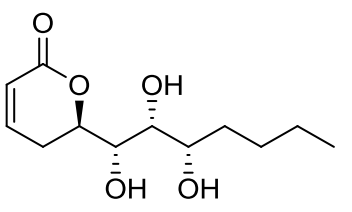

deacetylboronolide 
Figure 1. The reported structure of tetradenolide and related compounds.

The synthesis of the four diastereomers and making comparison of their ${ }^{1} \mathrm{H}$ and ${ }^{13} \mathrm{C}$ NMR spectral data with those of natural tetradenolide would be a crew to determine its relative stereochemistry. Therefore we planned to synthesize four diastereomers of tetradenolide (Figure 2).
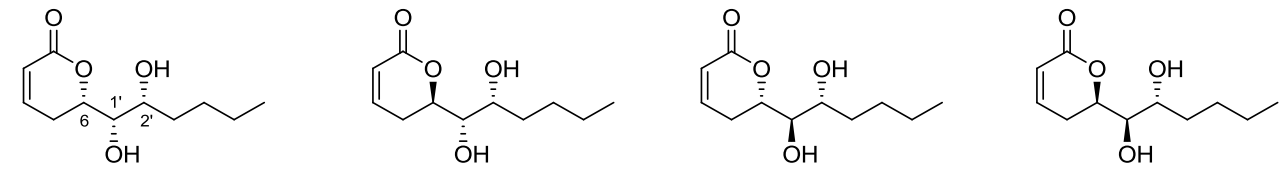

(6S, 1' $\left.S, 2^{\prime} R\right)$-tetradenolide (1a) $\quad\left(6 R, 1^{\prime} S, 2^{\prime} R\right)$-tetradenolide (1b) $\left(6 S, 1^{\prime} R, 2^{\prime} R\right)$-tetradenolide (1c) $\left(6 R, 1^{\prime} R, 2^{\prime} R\right)$-tetradenolide (1d)

Figure 2. The structures of four diastereomers of tetradenolide.

At first we began to synthesize $\left(6 S, 1^{\prime} S, 2^{\prime} R\right)$-tetradenolide (1a) starting from 1,3-propanediol (2). Monoprotection of 1,3-propanediol (2) with benzyl bromide in the presence of $\mathrm{NaH}$ followed by oxidation with $\mathrm{SO}_{3} \cdot$ pyridine afforded aldehyde $\mathbf{3}$. Alkylation of the 1-hexyne with aldehyde $\mathbf{3}$ using $n$-BuLi gave $\mathbf{4}$ which was subjected to reduction with $\mathrm{LiAlH}_{4}$ in THF under reflux to furnish $E$-allylic alcohol 5. Oxidation of 5 with DessMartin periodonane led to enone 6. ${ }^{7}$ Enone 6 was subjected to the Sharpless asymmetric dihydroxylation using $\mathrm{AD}$ mix $\beta$ to give diol 7 in $97 \%$ ee analyzed by Mosher ester derivative. ${ }^{8}$ Protection of the resulting diol with 2,2dimethoxypropane in the presence of PPTS afforded $\mathbf{8}$. Reduction of the ketone $\mathbf{8}$ with L-Selectride gave $\mathbf{9}$ in a single deiastereomer. ${ }^{9}$ To confirm the stereochemistry of newly formed oxymethine carbon, advanced Mosher method was used (supplementary content). ${ }^{10}$ We confirmed that this carbinol center possessed $S$ configuration. Secondary hydroxy group of $\mathbf{9}$ was protected as ethoxyethoxy group to afford $\mathbf{1 0}$ subsequent removal of benzyl group with $\mathrm{Na}$ in liquid $\mathrm{NH}_{3}$ followed by oxidation with Dess-Martin periodonane furnished aldehyde 11. The resultant aldehyde 11 was subjected to $Z$-selective Horner-Emmons reaction using diphenyl phosphonoacetate to afford 12 with 1:19 of E:Z ratio. ${ }^{11}$ Finally, 12 was treated with acid in THF- $\mathrm{H}_{2} \mathrm{O}$ under reflux to give $(6 S, 1$ 'S 2' $R$ )-tetradenolide (1a) (Scheme 1).
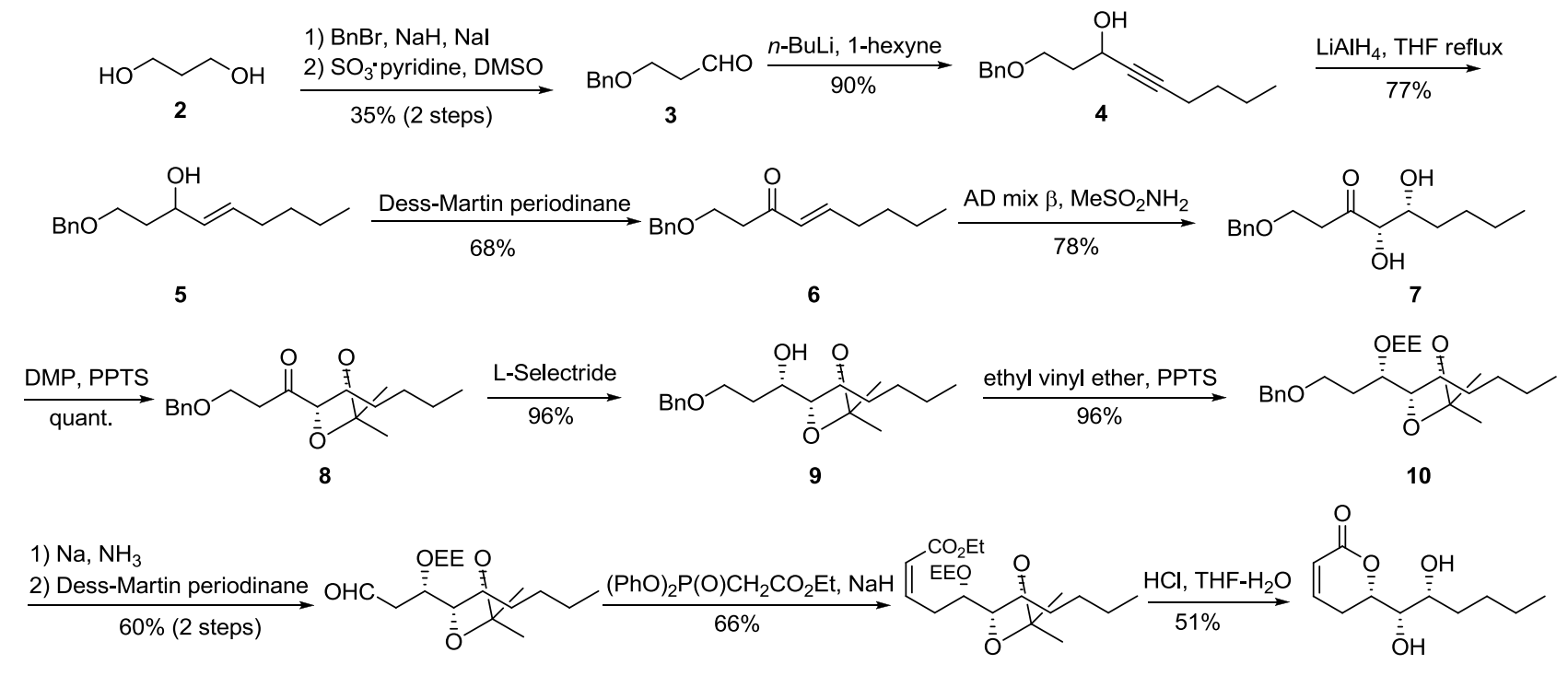
Scheme 1. Synthesis of $\left(6 S, 1^{\prime} S, 2^{\prime} R\right)$-tetradenolide (1).

Synthesis of $\left(6 R, 1^{\prime} S, 2^{\prime} R\right)$-tetradenolide (1b) was started from 9 which was an intermediate for the synthesis of $1 \mathbf{a}$. The secondary hydroxy group of $\mathbf{9}$ was inverted using Mitsunobu reaction with $p$-nitrobenzoic acid in the presence of DEAD and $\mathrm{PPh}_{3} .{ }^{12}$ Hydrolysis of $p$-nitrobenzoyl ester with methanolic $\mathrm{NaOH}$ gave 13. Compound 13 was converted to $\left(6 R, 1^{\prime} S, 2^{\prime} R\right)$-tetradenolide (1) as described in the synthesis of $\mathbf{1 a}$ (Scheme 2).

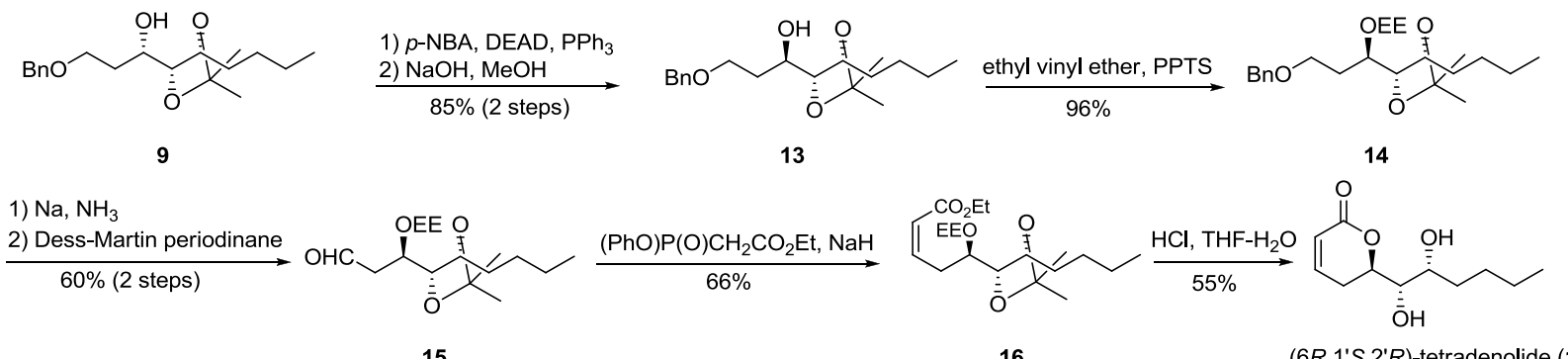

Scheme 2. Synthesis of (6R,1'S,2'R)-tetradenolide (1b).

Synthesis of $\left(6 S, 1^{\prime} R, 2^{\prime} R\right)$-tetradenolide (1c) was started from D-ribose (17). ${ }^{13}$ Protection of the diol at 2,3position with acetone in the presence of sulfric acid followed by Wittig reaction with $\mathrm{CH}_{3} \mathrm{P}^{+} \mathrm{Ph}_{3} \mathrm{I}^{-}$afforded diol 18 . Introduction of the triisopropyl benzenesulfonyl (Tris) group at primary hydroxy group under basic condition followed by treating with $\mathrm{NaH}$ gave terminal epoxide 19. Alkylation of 19 using $\mathrm{C}_{3} \mathrm{H}_{7} \mathrm{MgCl}$ in the presence of $\mathrm{CuI}$ gave 20. Protection of the resulting secondary hydroxy group as MOM ether followed by hydroboration using 9-BBN and treatment with $\mathrm{NaOH}$ and $\mathrm{H}_{2} \mathrm{O}_{2}$ furnished 21. Compound 21 was converted to $\left(6 S, 1^{\prime} R, 2^{\prime} R\right)$ tetradenolide (1c) as described in the synthesis of 1a (Scheme 3).

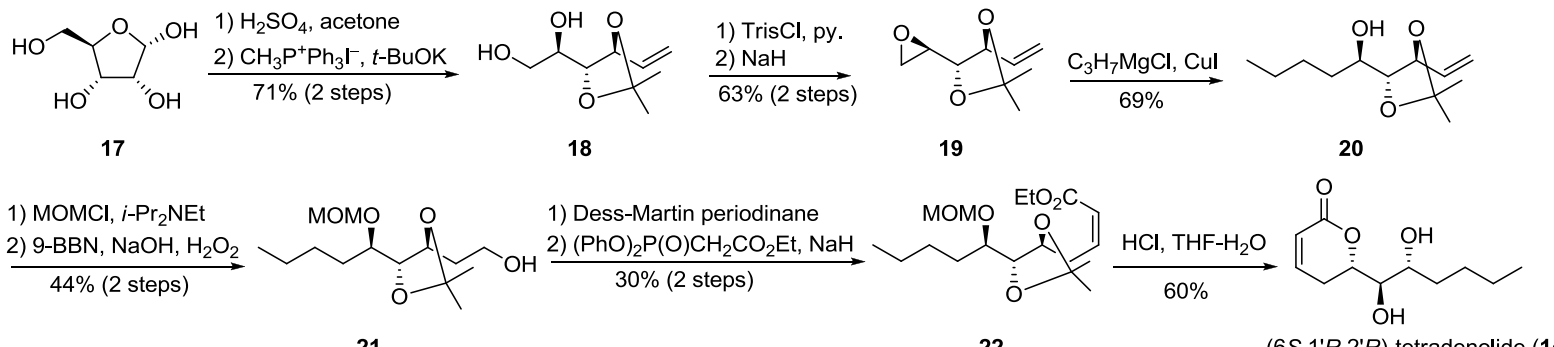

Scheme 3. Synthesis of $\left(6 S, 1^{\prime} R, 2^{\prime} R\right)$-tetradenolide (1c).

Next, we began to synthesize $\left(6 R, 1^{\prime} R, 2^{\prime} R\right)$-tetradenolide (1d). Alkylation of 4-butyn-1-ol (23) with 1-pentanal (24) using $n$-BuLi gave 25 which was subjected to reduction with $\mathrm{LiAlH}_{4}$ in THF under reflux to furnish $E$-allylic alcohol 26. Protection of the primary hydroxy group of $\mathbf{2 6}$ with TBDPSCl in the presence of $\mathrm{Et}_{3} \mathrm{~N}$ and DMAP afforded 30. Oxidation of the secondary hydroxy group of 27 with Dess-Martin periodinane gave enone 28. Enone 28 was subjected to the Sharpless asymmetric dihydroxylation using AD mix $\beta$ to give diol 29 in $97 \%$ ee analyzed by Mosher ester derivative. ${ }^{8}$ Protection of the resulting diol with 2,2-dimethoxypropane in the presence of PPTS afforded 30. Reduction of the ketone $\mathbf{3 0}$ with L-Selectride gave $\mathbf{3 1}$. To confirm stereochemistry of the newly formed oxymethine carbon, advanced Mosher method was used and this carbinol center was confirmed to 
be $S$ configuration (supplementary content). ${ }^{10}$ The secondary hydroxy group of $\mathbf{3 1}$ was inverted using Mitsunobu reaction with $p$-nitrobenzoic acid in the presence of DEAD and $\mathrm{PPh}_{3}$. Hydrolysis of $p$-nitrobenzoyl ester with methanolic $\mathrm{NaOH}$ gave 32. Protection of the resulting secondary hydroxy group as MOM ether followed by deprotection of the TBDPS group using TBAF gave $\mathbf{3 3}$ Compound $\mathbf{3 3}$ was converted to $\left(6 R, 1^{\prime} R, 2^{\prime} R\right)$ tetradenolide (1d) as described in the synthesis of $\mathbf{1 a}$ (Scheme 4).

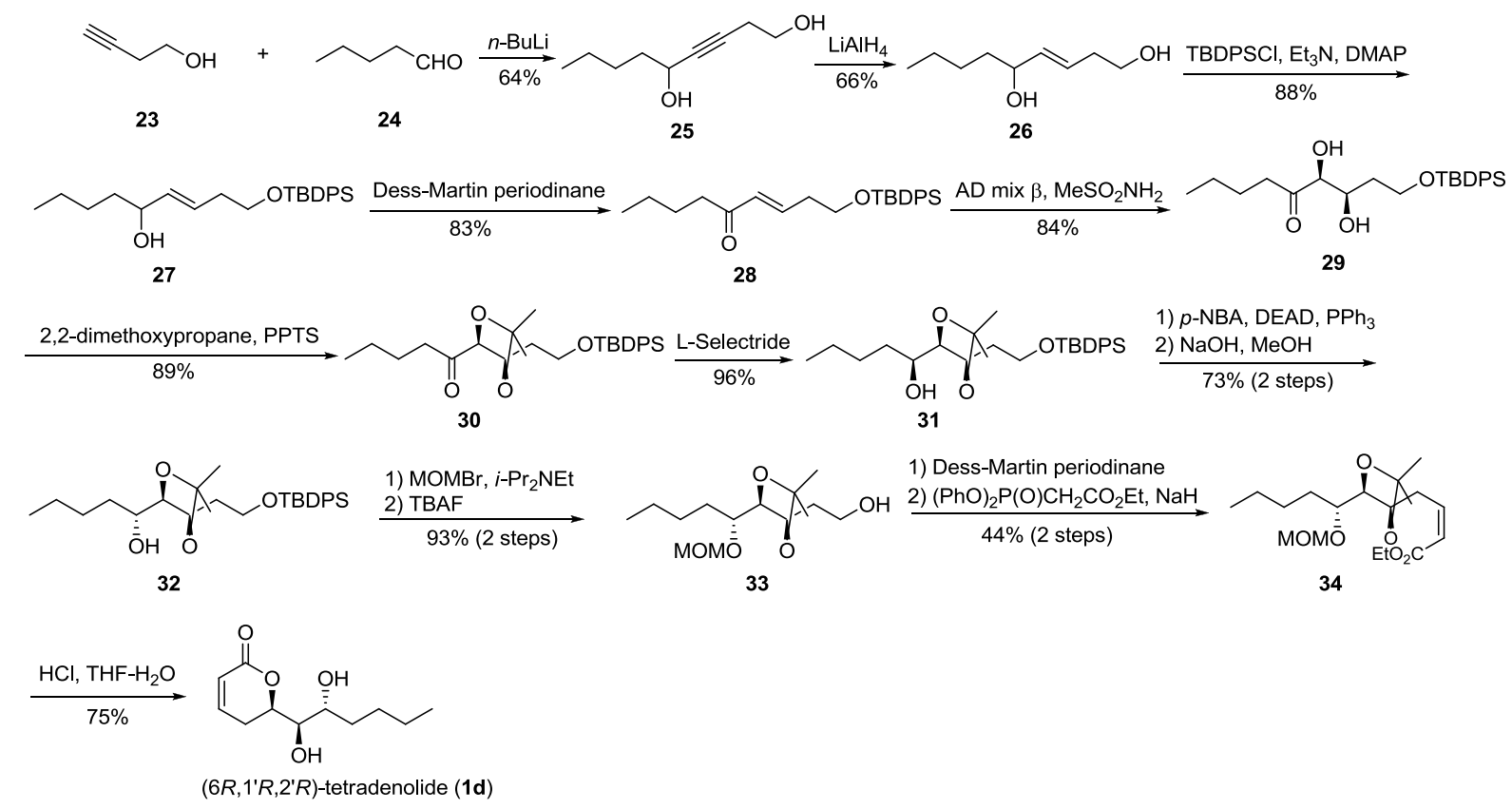

Scheme 4. Synthesis of (6R,1'R,2'R)-tetradenolide (1d).

As to the compounds $\mathbf{1 a}$ and $\mathbf{1 b}$, structurally similar compounds $\mathbf{3 5}$ and $\mathbf{3 6}$ were synthesized by Rúveda and coworkers who described the stereoselective transformation of the naturally abundant argentilactone in $1988 .{ }^{14}$ The ${ }^{13} \mathrm{C}$ NMR spectral data of carbinol centers of $\mathbf{1 a}$ and $\mathbf{1 b}$ were quite similar to those of $\mathbf{3 5}$ and $\mathbf{3 6}$, respectively (Figure 3).

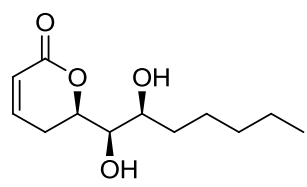

35

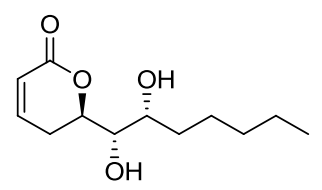

36

Figure 3. The related compounds $\mathbf{3 5}$ and $\mathbf{3 6}$ which were synthesized by Rúveda and co-workers.

As four diastereomers of tetradenolide were in hand, we compared their spectral data with those of the reported values to determine the relative stereochemistry. As to the ${ }^{1} \mathrm{H}$ NMR spectra, it is rather difficult to compare because the range of the chemical shifts of reported ${ }^{1} \mathrm{H}$ NMR spectra had a broad range (see supplementary information). Thus we focused on analyzing ${ }^{13} \mathrm{C}$ NMR spectra. The chemical shifts of ${ }^{13} \mathrm{C}$ NMR of natural one and synthetic 1a-1d were different especially C-6 and C-2' carbons. Therefore we could not determine the relative stereochemistry of tetradenolide (Figure 4). 


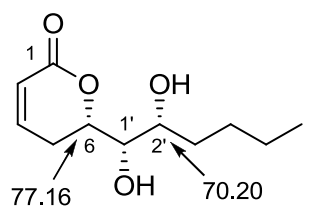

natural tetradenolide

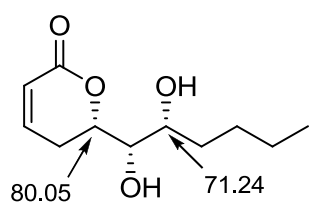

1a

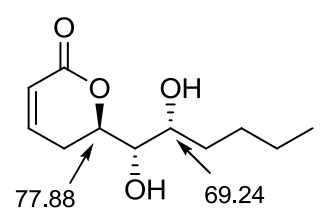

1b

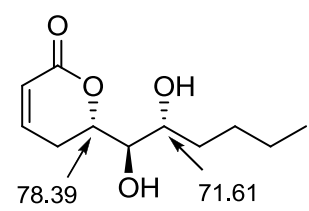

$1 c$

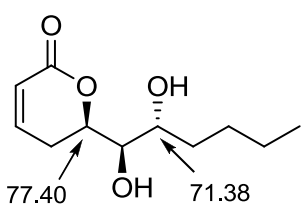

1d

Figure 4. The difference of chemical shift of ${ }^{13} \mathrm{C}$ NMR data of synthetic 1a-1d and natural tetradenolide.

Thus we carefully examined the ${ }^{13} \mathrm{C}$ NMR data of the related compounds of tetradenolide. ${ }^{2}$ We noticed that the ${ }^{13} \mathrm{C}$ NMR data of deacetylboronolide synthesized by Trost and co-worker were quite similar to those of tetradenolide (Table 1). ${ }^{15}$ Thus we synthesized deacetylboronlide to examine its ${ }^{13} \mathrm{C}$ NMR spectra in detail. ${ }^{16} \mathrm{We}$ found that the signals of ${ }^{13} \mathrm{C}$ NMR at C-1' and C-2' positions of deacetylboronolide were completely overlapped using HMQC experiment. ${ }^{16}$ Therefore, it was possible that the ${ }^{13} \mathrm{C}$ NMR of deacetylboronolide was misread as tetradenolide. ${ }^{1}$

Table 3. ${ }^{13} \mathrm{C}$ NMR data of tetradenolide and deacetylboronolide.

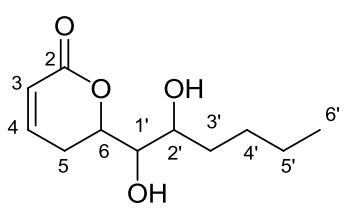

tetradenolide

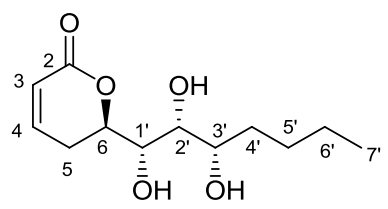

deacetylboronolide

\begin{tabular}{ccccc}
\hline position & tetradenolide & position & deacetylboronolide (Trost et al. $)^{a}$ & deacetylboronolide (by us) \\
\hline 2 & 164.02 & 2 & 163.98 & 164.10 \\
3 & 120.95 & 3 & 120.90 & 120.84 \\
4 & 146.11 & 4 & 146.09 & 146.21 \\
5 & 25.79 & 5 & 25.75 & 25.73 \\
6 & 77.16 & 6 & 77.12 & 77.15 \\
& & $1^{\prime}$ & 76.74 (overlapped with solvent) & 74.24 \\
$1^{\prime}$ & 74.36 & $2^{\prime}$ & 74.30 & 74.24 \\
$2^{\prime}$ & 70.20 & $3^{\prime}$ & 70.14 & 70.20 \\
$3^{\prime}$ & 33.46 & $4^{\prime}$ & 33.42 & 33.36 \\
$4^{\prime}$ & 27.67 & $5^{\prime}$ & 27.64 & 27.64 \\
$5^{\prime}$ & 22.62 & $6^{\prime}$ & 22.59 & 22.59 \\
$6^{\prime}$ & 14.00 & $7^{\prime}$ & 13.98 & 13.99 \\
\hline
\end{tabular}

${ }^{a}$ Trost and co-worker reported that the peak of $76.74 \mathrm{ppm}$ was observed. ${ }^{13}$ However, we could not observe this signal in the HMQC spectrum and found that both of C-1' and C-2' signals were overlapped at 74.24 ppm. ${ }^{14}$

As to the EI-MS spectrum of natural tetradenolide, Puyvelde et al. reported that $\mathrm{M}^{+}$could not be observed. We also measured EI-MS spectra of 1a-1b and found that only tiny signals of $\mathrm{M}^{+}$were observed. Puyvelde et al. prepared bis- $O$-TMS derivative of natural tetradenolide and reported that $\mathrm{M}^{+}(358,0.2 \%)$ was observed at $70 \mathrm{eV}$. 
We also prepared bis- $O$-TMS derivative of $\mathbf{1 b}$ using bis(trimethylsilyl)acetamide (BSA) and measured EI-MS at $70 \mathrm{eV}$. However, $\mathrm{M}^{+}(358,0.2 \%)$ was not detected but $(\mathrm{M}-\mathrm{Me})^{+}(343),\left(\mathrm{M}-\mathrm{C}_{4} \mathrm{H}_{9}\right)^{+}(301)$, and $\left(\mathrm{M}-\mathrm{C}_{6} \mathrm{H}_{14}\right)^{+}(272)$ were observed. The pattern of fragmentation was different from that of reported one of natural tetradenolide derivative. ${ }^{1}$ We also prepared tris- $O$-TMS derivative of (+)-deacetylboronolide and measured EI-MS at $70 \mathrm{eV} .{ }^{1}$ As Puyvelde et al. reported, m/z $358(0.2 \%)$ was observed and the pattern of fragmentation was similar to that of natural tetradenolide derivative except that the signals of $(\mathrm{M}-\mathrm{Me})^{+}(445),\left(\mathrm{M}-\mathrm{C}_{4} \mathrm{H}_{9}\right)^{+}(403)$, and $\left(\mathrm{M}-\mathrm{C}_{6} \mathrm{H}_{14}\right)^{+}(374)$ were observed.

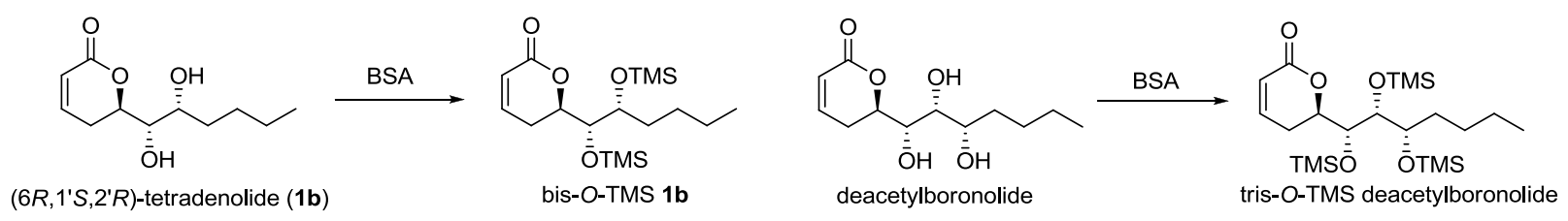

Figure 4. Preaparation of TMS derivatives of $1 \mathrm{~b}$ and deacetylboronolide.

We measured CI-MS spectra of 1a-1d and deacetylboronolide. We could observe $(\mathrm{M}+\mathrm{H})^{+}$clearly. We found that CI-MS was effective to obtain satisfied data for hydroxylated $\delta$-lactones.

The melting point value of reported tetradenolide was $\left(102.8-103^{\circ} \mathrm{C}\right)$ also very close to that of deacetylboronolide synthesized by us $\left(101-102{ }^{\circ} \mathrm{C}^{18}\right)$ lit. $\left\{\left(99-100^{\circ} \mathrm{C},{ }^{2 a} 101^{\circ} \mathrm{C}^{17}\right)\right\} .{ }^{1}$ The sample of natural tetradenolide and its spectral data are no longer available, ${ }^{18}$ however, it is highly possible that the structure of tetradenolide is deacetylboronolide from the reasons as follows: 1) ${ }^{13} \mathrm{C}$ NMR spectral data of natural tetradenolide was identical with those of (+)-deacetylboronolide; 2) The melting point value of natural tetradenolide was very close to that of (+)-deacetylboronolide; 3) natural tetradenolide and deacetylboronolide were isolated from the same plant, Tetradenia riparia. . $^{1,2}$

In conclusion, four diastereomers of tetradenolide, ${ }^{15}$ a cytotoxic $\alpha$-pyrone isolated from Tetradenia riparia, were synthesized. The ${ }^{1} \mathrm{H}$ and ${ }^{13} \mathrm{C}$ NMR spectral data of the four diastereomers were not consistent with those of reported values of natural tetradenolide. The detailed investigation of the ${ }^{13} \mathrm{C}$ NMR data and melting point data of the related compounds led us to revise the structure of tetradenolide as deacetylboronolide.

\section{Acknowledgements}

We thank Prof. Dr. De Kimpe, N. for his valuable information about $\alpha$-pyrone natural products. This work was supported in part by JSPS KAKENHI Grant Number 24580160 to H. M.

\section{References and notes}

1. Van Puyvelde, L.; De Kimpe, N. Phytochemistry 1998, 49, 1157. 
2. (a) Van Puyvelde, L.; Dube, S.; Uwimana, E.; Uwera, C.; Domisse, R. A.; Esmans, E. L.; Van Schoor, O.; Vlietinck, A. Phytochemistry 1979, 18, 1215; (b) Van Puyvelde, L.; De Kimpe, N.; Dube, S.; Chagnon-Dube, M.; Boily, Y.; Borremans, F.; Schamp, N.; Anteunis, M. J. O. Phytochemistry 1981, 20, 2753.

3. Franca, N. C.; Polonsky, J. C. R. Hebd. Seances, Acad. Sci., Ser. C. 1971, 273, 439.

4. Davies-Coleman, M. T.; Rivett, D. E. A. Phytochemistry 1987, 26, 3047.

5. Watt, J. M.; Brandwijk, M. G. B. The Medicinal and Poisonous Plants of Southern and Eastern Africa, Livingston: Edinburgh, 1962, p516.

6. (a) Nagano, H.; Yasui, H. Chem. Lett. 1992, 1045. (b) Honda, T.; Horiuchi, S.; Mizutani, H.; Kanai, K. J. Org. Chem. 1996, 61, 4944. (c) Ghosh, A. K.; Bilcer, G. Tetrahedron Lett. 2000, 41, 1003. (d) Trost, B. M.; Yeh, V. S. C. Org. Lett. 2002, 4, 3513. (e) Carda, M.; Rodoríguez, S.; Segovia, B.; Marco, J. A. J. Org. Chem. 2002, 67, 6560. (f) Chandrasekhar, M.; Chandra, K. L.; Singh, V. K. J. Org. Chem. 2003, 68, 4039. (g) Hu, S. -G.; Hu, T. -S.; Wu, Y. -L. Org. Biomol. Chem. 2004, 2, 2305. (h) Naidu, S. V.; Gupta, P.; Kumar, P. Tetrahedron Lett. 2005, 46, 2129. (i) Boruwa, J.; Barua, N. C. Tetrahedron 2006, 62, 1193. (j) Kumar, P.; Naidu, S. V. J. Org. Chem. 2006, 71, 3935. (k) Prasad, K. R.; Anbarasan, P. Tetrahedron: Asymmetry 2006, 17, 1146. (1) Raghavan, S.; Krishnaiah, V. Tetrahedron Lett. 2006, 47, 7611. (m) Yamauchi, S. ; Isozaki, Y.; Nishimura, Y.; Tsuda, H.; Nishiwaki, T.; Shuto, Y. Biosci. Biotechnol. Biochem. 2012, 76, 1708. (n) Reddy, B. V. S.; Reddy, V. V.; Praneeth, K. Tetrahedron Lett. 2014, 55, 1398.

7. Dess, D. B.; Martin, J. C. J. Am. Chem. Soc. 1991, 113, 7277.

8. Kolb, H.; VanNiewenhze, M. S.; Sharpless, K. B. Chem. Rev. 1994, 94, 2483.

9. Ghosh A. K.; Bilcer, G. Tetrahedron Lett. 2000, 41, 1003.

10. Ohtani, I.; Kusumi, T.; Kashman, Y.; Kakisawa, H. J. Am. Chem. Soc. 1991, 113, 4092.

11. (a) Ando, K. Tetrahedron Lett. 1995, 36, 410; (b) Ando, K. J. Org. Chem. 1997, 62, 1934.

12. Mitsunobu, O. Synthesis 1981, 1.

13. (a) Srihari, P.; Kumaraswamy, B.; Yadav, J. S. Terahedron 2009, 65, 6304; (b) Srihari, P.; Kumaraswamy, B.; Rao, G. M.; Yadav, J. S. Terahedron: Asymmetry 2010, 21, 106.

14. Signorella, S. R.; Cravero, R. M.; Sala, L. F.; Rúveda, E. A. Synth. Commun. 1988, 18, 1935.

15. Trost, B. M.; Yeh, V. S. C. Org. Lett. 2002, 4, 3513.

16. Kurogome, Y.; Hattori, Y.; Makabe, H. Tetrahedron Lett. 2014, 55, 2822.

17. Chandrasekhar, M.; Chandra, K. L.; Singh, V. K. J. Org. Chem. 2003, 68, 4039. 
18. Personal communication with Prof. Dr. De Kimpe, N. 